\title{
USO DA TERAPIA ESPELHO NA AMPLITUDE DE MOVIMENTO E FUNÇÃO DO MEMBRO INFERIOR EM PACIENTES HEMIPARÉTICOS PÓS-AVE
}

\author{
Bruno Vieira Cortez ${ }^{1}$ \\ Lívia Danyelle Viana Lima² \\ Janaína De Moraes Silva ${ }^{3}$
}

Resumo: O exercício associado a terapia espelho potencializa a retenção de habilidades, melhorando o desempenho de atividades motoras de indivíduos hemiparéticos pós-AVE. Este estudo objetivou a análise do efeito da terapia espelho na amplitude de movimento e funcionalidade do membro inferior. Amostra composta de 11 participantes, com hemiparesia em membro inferior, submetidas a fisioterapia convencional. A intervenção constituiu de 10 atendimentos, 30 minutos diários e três vezes por semana. Para avaliação foram usados: Goniometria; Escala Modificada de Ashworth (EMA); Escala de Força de Oxford; Cadência de Subida e Descida de Escada; Time Up And Go Test. Os dados foram coletados antes e após a intervenção da Terapia Espelho e comparados. Segundo resultados do estudo a Terapia Espelho proporcionou ganhos na $A D M$ e função do membro inferior parético pós-AVE, porém não interferiu na espasticidade.

Palavras-chave: Acidente Vascular Encefálico; Hemiparesia; Retroalimentação visual.

\footnotetext{
${ }^{1}$ Fisioterapia/Faculdade Maurício De Nassau, Brasil. E-mail: bruno_cortez14@hotmail.com.

2 Fisioterapia/Faculdade Maurício De Nassau, Brasil. E-mail: liviadanyellevl@hotmail.com.

${ }^{3}$ Fisioterapia/Faculdade Mauricio de Nassau; UESPI, Brasil. E-mail: fisiojanainams@gmail.com.
} 